\title{
A Sociologia Digital: um desafio para o século XXI
}

LEONARDO FERNANDES NASCIMENTO"

\section{Resumo}

As características da cultura e da sociedade se alteraram profundamente na medida em que novas formas de comunicação dependentes das tecnologias digitais adquiriram um uso generalizado, modificando o modo como buscamos e produzimos informação. Entretanto, as ciências sociais ainda analisam este fenômeno de maneira tímida, negligenciando os efeitos das tecnologias digitais nas sociedades e, sobretudo, no próprio ofício da sociologia. O presente artigo descreve o modo como as mudanças tecnológicas representam um dos grandes desafios para a sociologia do século XXI, argumentando que é necessário não apenas o aperfeiçoamento de aspectos tecnológicos da pesquisa - como, por exemplo, o domínio de softwares de análise qualitativa e quantitativa e de redes sociais digitais - mas, fundamentalmente, o avanço em termos do significado epistemológico destas tecnologias para a imaginação sociológica. Na primeira seção, é apresentada a proposta da sociologia digital. Em seguida, descreve-se o fenômeno da produção massiva de dados digitais e os desafios que tal contexto coloca para a sociologia. A terceira seção avalia as implicações para a sociologia do uso de softwares. A última seção defende a necessidade urgente de uma atualização teórico-metodológica da sociologia frente à produção massiva de dados digitais. Por fim, argumenta-se que a sobrevivência da sociologia dependerá da instrumentalização tecnológica aliada a uma reflexão diante de um novo horizonte de questões da era digital.

Palavras-chave: Sociologia Digital, Big data, CAQDAS.

\footnotetext{
* Universidade Federal da Bahia (Brasil)
} 


\section{Digital sociology: a challenge to the 21st century}

\section{Abstract}

The dissemination of new kinds of communication based on digital technologies have changed dramatically the characteristics of culture and society, modifying the way we search and produce information. However, the analysis of this phenomenon by the social sciences is still shy and neglect the effects of digital technologies on society and, especially, on sociology itself. This article points to the challenges posed by technological changes to the sociology of 21st century, arguing that it is necessary not only to improve technological aspects of research - for example, command of software for qualitative and quantitative analysis and analysis of digital social networks - but also, and fundamentally, to advance in terms of the epistemological impact of these technologies for the sociological imagination. The first section presents the fundaments of digital sociology. The following describes the phenomenon of mass production of digital data and the challenges that this environment raises for sociology. The third section assesses the implications of the use of software for sociology. The last section makes the case that there is an urgent need for theoretical and methodological update of sociology in the face of mass production of digital data. Finally, it is argued that the future of sociology depends on its technological instrumentation combined with reflection in sight of a new horizon of issues in the digital age.

Keywords: Digital Sociology. Big data, CAQDAS.

Carthago delenda est

\section{Introdução}

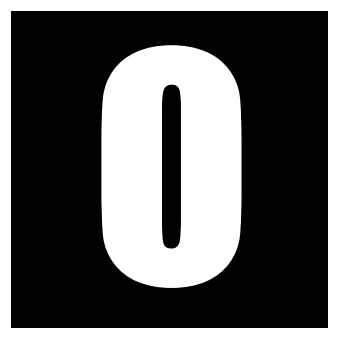

s computadores fazem parte da vida em sociedade. Sob os mais diversos formatos, tamanhos e funções, eles conseguiram alcançar praticamente todos os ambientes sociais: do complexo painel de controle das grandes in-

dústrias às prefeituras das pequenas cidades; do quarto de dormir, passando pelos consultórios médicos, dentro dos motores dos carros modernos e dos bolsos de adolescentes, adultos e de alguns ido- 
sos e crianças. A difusão praticamente viral dos computadores pessoais, dos smartphones, laptops e tablets parece extrapolar, até certo ponto, algumas das conhecidas barreiras de estratificação social, de classe, de gênero ou de idade. Por conseguinte, não é difícil perceber que uma boa parte dos processos sociais passam a depender, em algum momento, do funcionamento dessas máquinas.

Uma das consequências disso é que a cultura, as relações sociais e as instituições se alteraram profundamente, na medida em que novas formas de comunicação dependentes das tecnologias digitais adquiriram um uso generalizado (Horst; Miller, 2012; Prior; Orton-Johnson, 2013; Jordan, 2014; Lupton, 2015). Obviamente que tais transformações sociais impactaram o modo como fazemos ciência, reverberando, também, na disciplina da sociologia. Alguns autores chegam a defender que estamos diante de um modo completamente novo de fazer sociologia (Wynn, 2009; Beer et al., 2007, 2013; Lupton, 2015). Segundo eles, existiriam mudanças urgentes na aquisição das competências necessárias para o ofício de sociólogo, especialmente em relação ao uso de novas tecnologias no ensino, na pesquisa e na divulgação científica da sociologia.

...na medida em que as tecnologias de informação e comunicação baseadas na Internet transformaram a sociedade, elas transformaram, também, a disciplina da sociologia. De forma mais geral, estas tecnologias alteraram a forma como cientistas e acadêmicos de todas as áreas buscam e referenciam informação relevante, inclusive a literatura acadêmica. Além disso, abordagens específicas à pesquisa sociológica também se transformaram. (Witte, 2012, p. 83)

O presente artigo vai desenvolver essas questões articulando autores que tratam da temática do novo campo denominado sociologia digital com problemas de caráter teórico-metodológico sobre o progressivo uso de softwares nas ciências sociais. Na primeira seção eu vou delinear a proposta da sociologia digital, fazendo um breve percurso histórico do seu surgimen- 
to. Em seguida, será descrito o fenômeno da produção massiva de dados digitais e os desafios que tal contexto coloca para a sociologia. A terceira seção aborda as implicações para o exercício e a imaginação sociológica do uso de softwares nas tradicionais análises qualitativas e quantitativas. A última seção defende a necessidade urgente de uma atualização teórico-metodológica da sociologia frente aos desafios da produção massiva de dados digitais. Por fim, argumenta-se que a sobrevivência da disciplina da sociologia dependerá da instrumentalização tecnológica aliada a uma reflexão diante de um novo horizonte de questões da era digital.

\section{1 - A proposta da sociologia digital}

Há quinze anos atrás, no ano de 2000, o sociólogo da Universidade de Chicago Andrew Abbott, em um visionário artigo denominado Reflections on the Future of Sociology, apresentou um conjunto de desafios para o futuro da sociologia. Um desses desafios estava diretamente relacionado com as transformações tecnológicas e a produção massiva de dados. Sua preocupação estava orientada não apenas em relação ao número de casos que a tecnologia havia tornado virtualmente ilimitado, mas especialmente em relação ao grande número de variáveis que agora se tornaram acessíveis em poucas operações (Abbott, 2000). Desse modo, o desafio que nos é colocado, aponta Abbot, é o de "encontrar padrões nestes dados monumentalmente detalhados"(ib. p. 298). Para ele, mais do que um problema quantitativo, existiria o desafio qualitativo de construir instrumentais teórico-metodológicos para a produção de inteligibilidade sociológica desses dados. Em seguida, nos sugere uma alarmante argumentação:

O fato nu e cru é que a sociologia está lamentavelmente despreparada para lidar com esse problema: não temos nem as ferramentas analíticas, nem a imaginação conceitual necessária. Nossas aparelhagens metodológicas foram 
projetadas para investigar as relações entre um pequeno número de variáveis e são inúteis para grande escala de reconhecimento de padrões ou, como temos pejorativamente rotulado, para a dragagem de dados (data dredging). (Abbott, 2000, p. 298)

Após quinze anos, o fenômeno descrito por Abbot apenas se intensificou. Enquanto outros departamentos das ciências naturais foram profundamente modificados pelas mudanças tecnológicas provocadas por computadores e acesso à informação, as ciências sociais permanecem estagnadas em seus moldes originais (Christakis, 2013). É tarefa da sociologia digital retomar as preocupações apresentadas acima, obviamente recalibradas para o horizonte atual. Como podemos avaliar o impacto e os desafios destas transformações da sociedade digital para a sociologia? Por que a formação em sociologia frequentemente conduz os estudantes e professores a uma "tecnofobia" (Back, 2012, p. 22) ou à posição do "sociólogo relutante" (Farrell; Petersen, 2010) (ambas expressões que traduzem a rejeição e desconfiança do uso de tecnologia nas mais diversas funções do exercício do sociólogo)? E, de maneira mais dramática, qual o futuro da sociologia diante desse contexto da "era da informação" e do "mundo digital"? Vejamos como a sociologia digital responde a estas questões.

O termo sociologia digital apareceu pela primeira vez na literatura acadêmica de língua inglesa, em 2009, no artigo Digital Sociology: Emergent Technologies in the Field and the Classroom (Sociologia digital: tecnologias emergentes no campo e na sala de aula) do então professor do Smith College, Prof. Jonathan Wynn. Tendo como inspiração a obra Telling About Society, de Howard Becker, suas preocupações estavam relacionadas a aspectos metodológicos da pesquisa, tais como uso de gravadores e máquinas fotográficas digitais, e as mudanças em sala de aula através de apresentações audiovisuais. Ele descreve o que seria o próximo estágio da sociologia e que "deveríamos treinar os estudantes para serem reflexivos 
em relação à tecnologia" (Wynn, 2009, p. 449). Desde então, têm surgido publicações buscando delinear o campo da sociologia digital.

Em 2013, foi publicada uma coletânea de trabalhos denominada Digital Sociology: Critical Perspectives (Sociologia digital: perspectivas críticas) reunidas em torno da "necessidade de a sociologia se deslocar conceitualmente para além das oposições binárias de virtual/real e continuidade/transformação" que, segundo os organizadores, têm caracterizado o debate existente sobre a pesquisa em internet e os estudos acerca da interseção entre tecnologia, cultura e sociedade (Prior; Orton-Johnson, 2013, p. 2). Os diferentes capítulos organizados nos eixos temáticos "relacionamentos", "espaços", "estruturas", "mediações" e "práticas" delineiam os grandes temas que marcam a sociedade contemporânea e que, por este motivo, constituem os interesses da sociologia digital: a mudanças dos relacionamentos e nas comunidades, provocadas pelas redes sociais digitais; as alterações na relação com o espaço; o crescimento e a disseminação da vigilância; a desigualdade digital e o capitalismo da informação; o sistema de ensino e o cuidado com a saúde na era digital.

Mais recentemente, em 2015, nós temos a publicação do livro Digital Sociology da professora e pesquisadora Debora Lupton. O livro tem como argumentação central a constatação das mudanças digitais em absolutamente todos os fenômenos de estudo da sociologia e a consequente necessidade de uma prática sociológica digitalizada:

Eu argumentaria que a sociologia precisa fazer o estudo das tecnologias digitais central às suas atribuições. Todos os tópicos que os sociólogos agora pesquisam e ensinam estão inevitavelmente conectados às tecnologias digitais, quer eles se concentrem na sociologia da família, da ciência, da saúde e medicina, do conhecimento, da cultura, da economia, do emprego, da educação, do trabalho, do gênero, do risco, do envelhecimento, da raça e etnicidade. Estudar a sociedade digital é se concentrar em muitos aspectos que 
têm sido preocupações centrais para os sociólogos: individualidade, identidade, embodiment, as relações de poder e as desigualdades sociais, redes sociais, estruturas sociais, instituições sociais e teoria social. (Lupton, 2015, p. 8)

Deste modo, a autora vai sugerir quatro campos distintos de preocupações da sociologia digital: a) a prática profissional digitalizada: o uso de ferramentas digitais para propósitos profissionais; b) análise de dados digitais: usar dados digitais para a investigações qualitativas e quantitativas; c) análises sociológicas de uso de mídias digitais: pesquisar o impactos das mídias e redes sociais digitais para o comportamento do atores sociais; e d) sociologia digital crítica: realizar análises das mídias digitais com base nas teorias sociais (Lupton, 2015, p. 11). Cada um destes campos demandaria um esforço intelectual nas ciências sociais contemporâneas, na instrumentalização e no desenvolvimento do que a autora denomina de "habilidades computacionais" (ib., p. 25).

Embora ainda seja um movimento tímido, se comparado com outras áreas, os sociólogos já estariam usando, em maior ou menor extensão, muitos dos dispositivos digitais das sociedades contemporâneas. Desde aqueles dispositivos que se tornaram de certo modo "imprescindíveis", tais como editores de texto e planilhas (Office/OpenOffice), gravadores digitais, ebooks, celulares, máquinas fotográficas digitais etc., até ferramentas de divulgação científica como redes sociais digitais (p.ex. Twitter e Facebook), blogs e sites como LinkedIn, Academia.edu e outros do gênero. Este movimento vem, gradualmente, alterando a inserção da própria sociologia no cenário público, direcionando os seus resultados para audiências mais amplas que apenas o público acadêmico e com uma complexidade maior do que nos foi permitida até então na mídia de massa tradicional.

Enquanto a mídia de massa tradicional, especialmente a mídia de notícias, forneceu um importante fórum para comentários públicos, as novas mídias digitais oferecem muito 
Sociologias, Porto Alegre, ano 18, no 41, jan/abr 2016, p. 216-241

mais maneiras de fazer isso. Eles permitem que os sociólogos tenham mais controle sobre o teor das mensagens que pretendem divulgar em fóruns públicos, como estudiosos que são capazes de publicar material, sem [a necessidade] de um mediador. Em Blogs, no Twitter, gerenciando páginas do Facebook, editando verbetes da Wikipédia, engajando-se em sites de redes profissionais, como Academia.edu, ResearchGate e Linkedln, fazendo podcasts e vídeos no YouTube e assim por diante, são todos eles formas de empregar a mídia digital para fins acadêmicos profissionais (Lupton, 2015, p. 34)

Além disso, o exercício da sociologia não ficou incólume a todas estas mudanças, daí a ênfase em estudar os impactos das tecnologias digitais nos seus fundamentos epistemológicos e metodológicos.

A Sociologia Digital não trata apenas de sociólogos pesquisando e teorizando sobre como outras pessoas usam tecnologias digitais ou concentrando-se nos dados digitais produzidos através deste uso. A Sociologia Digital tem implicações muito mais amplas do que simplesmente estudar as tecnologias digitais, levantando questões sobre a prática da sociologia e a pesquisa social. Ela também inclui pesquisas sobre como os próprios sociólogos estão usando as mídias digitais sociais e outros como parte do seu trabalho (Lupton, 2015, p. 15)

Nesse novo contexto, a sociologia digital está interessada no modo como os indivíduos passam a ser produtores incessantes de dados digitais. Ao passar em ambientes sociais monitorados por câmeras, ao ativar o GPS do seu smartphone e fornecer sua localização georreferenciada, ao fazer login em seu email, ao frequentar websites, ao clicar em "likes" de redes sociais e ao fazer buscas no Google, a todo momento fornecemos algum tipo de informação às empresas que regulam todas essas redes e aparelhos. Estaríamos nos convertendo no que a sociologia digital denomina de digital data subjects ("sujeitos produtores de dados digitais") (Lupton, 2015, p. 7). 
Esse fenômeno levanta grandes preocupações do ponto de vista da privacidade e da segurança das pessoas, pois a grande maioria dos usuários - como veremos mais adiante - sequer imagina que os seus dados são utilizados por empresas como Google, Facebook, Microsoft e muitas outras. A sociologia digital confere, desse modo, especial atenção a estas questões, tentando assumir uma posição que supere a demonização da internet como instrumento de "hipervigilância" e controle sem cair, por outro lado, numa "tecnolatria" imponderada. Um exemplo disso é que, apesar do reconhecimento desta produção e uso dos dados pessoais, a sociologia digital incentiva o uso das redes sociais digitais para a produção de um e-profile ou perfil digital através do uso de blogs, de páginas pessoais, do Twitter e/ou Facebook (Lupton, 2015, p. 35).

\section{2 - A produção massiva de dados digitais: o fenômeno dos big data}

A consequência da disseminação global da internet e da captação online de dados através dos diversos canais de acesso e de uso dos softwares e redes sociais digitais acabou por intensificar o cenário descrito acima por Abbott, fomentando a criação de um novo campo interdisciplinar de estudos acerca da "maré crescente de dados digitais" (Witte, 2012, p. 55). São os estudos sobre big data ou "megadados": dados que são produzidos em alta velocidade, em grande volume e imensa variedade e que costumam apresentar grande complexidade.

As grandes corporações financeiras (Amazon, Netflix, Apple, Microsoft, etc.), as redes sociais digitais (Facebook, Twitter, Tumblr, Instagram, etc.) e os gerenciadores de busca (Google, Bing, etc.), todos eles dispõem atualmente de uma produção contínua e massiva de dados acerca do tipo e da amplitude de nossas interações sociais. Dados sobre gênero, raça, 
comportamento de consumo, migração, consumo cultural de música, filmes, imagens, são continuamente produzidos, e a quase totalidade da comunidade sociológica não tem acesso aos mesmos e, mesmo que tivesse, dificilmente seria capaz de analisá-los com as ferramentas analógicas da sociologia tradicional. Por esse motivo, os big data possuem um papel de destaque na sociologia digital como fonte de suas pesquisas.

Entretanto, ao se referir aos big data, a sociologia digital os reconhece como artefatos socioculturais que exercem efeitos concretos sobre a vida das pessoas e que, por este motivo, merecem uma atenção especial dos sociólogos. Em outras palavras, os big data não possuem uma existência autonomizada em relação ao mundo social, pois é na referência ao comportamento humano e às dinâmicas da vida em sociedade que eles precisam e devem ser pensados:

Big Data são vistos como oferecendo maior precisão e poder de predição para melhorar a eficiência, a segurança, o bem-estar e a geração ou gestão dos recursos. A capacidade das tecnologias digitais para a coleta, a mineração, o armazenamento e a análise dos dados são representados como superior a outras formas de conhecimento, oferecendo mais oportunidades do que nunca para aprofundar os comportamentos humanos. A partir de uma perspectiva sociológica crítica, no entanto, há muito mais a dizer sobre os big data enquanto artefatos socioculturais (Lupton, 2015, p. 45)

Embora muitos sociólogos possam contra-argumentar que as interações face a face, a observação imersa e a descrição densa dos fenômenos do mundo da vida constituam técnicas de investigação sociológica insubstituíveis, acredito que o manancial e a fertilidade sociológica dos big data nos conduz a considerar sua crescente importância e a necessidade de conhecimento da sociologia sobre como eles poderiam ser analisados. Sendo assim, as análises sociológicas da massiva produção de dados digitais não deveriam ser pensadas enquanto substitutos de uma forma ante- 
rior de fazer sociologia, nem como um modismo passageiro ou como algo restrito somente a um subcampo da sociologia, mas como instrumentos aliados capazes de ampliar as potencialidades dos métodos tradicionais e que demandam uma especialização particular que poucos dos sociólogos atuais se dispõem a aprender.

A sociologia digital ressalta ainda o fato de considerarmos criticamente o entusiasmo em relação aos big data em termos de suas potencialidades e limitações. Os big data devem ser encarados - da mesma forma que outros fenômenos - a partir de um velho princípio das ciências proposto por Francis Bacon, que foi enfatizado no nascimento da sociologia por Émile Durkheim (2007, p. 18) e posteriormente entoado como um mantra por Pierre Bourdieu (Bourdieu et al., 2004, p. 23-24): o combate às noções vulgares ou praenotiones (pré-noções). Assim como existem conceitos pré-construídos no mundo social que a sociologia não pode simplesmente contrabandear para dentro do seu campo sem direcionar a eles o crivo analítico da vigilância epistemológica, o mesmo deve ocorrer com relação aos dados digitais. Eles estariam submetidos a regras de produção e comercialização alheios aos objetivos científicos da sociologia. Em outras palavras, as lógicas que atuam em uma rede social digital possibilitando e fomentando a "representação digital do eu na vida cotidiana" ou, igualmente, os motivos que conduzem as pessoas a pesquisar termos em motores de busca como Google - ambas fontes inesgotáveis de big data - obedecem a motivações que devem ser discutidas antes de nos apropriarmos dos dados oriundos de tais fontes (Lupton, 2015, p. 30).

Além disso, a novidade dos big data não se refere aos dados em si. Grandes bases de dados existem desde que começaram os censos, o uso de telefones tradicionais em escala mundial, os números de voos que saem e chegam de um determinado aeroporto, etc. A maior novidade é a capacidade de acessar e analisar e cruzar variáveis com velocidade 
através de computadores pessoais e softwares relativamente acessíveis (Boyd; Crawford, 2012, p. 663). Sobre este aspecto, gostaria de sublinhar uma reflexão deixada de lado nos livros e artigos sobre sociologia digital mencionados e que, ao meu ver, possui uma relevância fundamental: os softwares de análise qualitativa auxiliada por computador. Conhecidos pelo seu acrônimo de língua inglesa CAQDAS (computer assisted qualitative data analysis) e surgidos na década de 80, atualmente estes softwares acompanham o movimento de uso massivo dos computadores pessoais, tornando-se progressivamente utilizados pelos pesquisadores e estudantes para tratar os big data digitais.

\section{3 - CAQDAS: a imaginação sociológica no contexto digital}

Não pretendo fazer um histórico do uso dos CAQDAS e nem ser extensivo nas vantagens e desvantagens específicas dos diferentes softwares disponíveis no mercado ${ }^{1}$. Atualmente, embora não tenhamos dados mais profundos, existem dois softwares que parecem dominar o cenário brasileiro por causa da oferta de cursos que aparecem nos grandes centros de pesquisa e nos diversos congressos. São eles os softwares Atlas. ti e NVivo de análise qualitativa de dados ${ }^{2}$. Uma rápida busca no portal Scielo ${ }^{3}$ restrita ao contexto brasileiro, e encontraremos 40 artigos das mais variadas áreas que citam o uso do Atlas.ti e 33 artigos que citam o uso do

\footnotetext{
${ }^{1}$ Para estas informações Cf. (Lage; Godoy, 2008; Mangabeira et al., 2001; Puebla, 2003; Teixeira; Becker, 2001)

${ }^{2}$ Ainda não existem softwares livres de análise qualitativa de dados, ao menos não com a sofisticação gráfica e de recursos que o Atlas.ti e o NVivo proporcionam. Convido o leitor e a leitora a olharem com atenção o pacote RQDA para a linguagem e o ambiente R de programação, ele está em constante atualização e muito em breve esta poderá ser uma alternativa não comercial para o uso em pesquisa (Huang, 2014).

${ }^{3}$ http://www.scielo.org/ acessado em 15 de jan. 2015.
} 
software NVivo. Embora sua utilidade não esteja restrita aos big data, é no tratamento destes dados que sentimos a potencialidade desses softwares.

Há aproximadamente dez anos, seria impossível fazer uma pesquisa de notícias através de CAQDAS, pois os principais jornais do Brasil ainda não estavam disponíveis para acesso em formato digitalizado. Seria preciso, portanto, muito tempo e esforço para poder selecionar e buscar as matérias que seriam do escopo do trabalho. Atualmente, bastam alguns poucos cliques e o uso de algumas linguagens de programação tais como R (R TEAM CORE, 2014) e Python ${ }^{4}$ para podermos fazer o download em massa, segundo determinadas palavras-chave, de milhões de matérias de jornal, de artigos científicos, de imagens, etc. Isso permite a montagem de grandes bancos de dados que, por sua vez, necessitam de instrumentos mais poderosos de busca e análise que, no passado recente, ainda não estavam disponíveis.

Entretanto, se olharmos mais de perto a estrutura desses aplicativos, poderemos perceber que eles extrapolam, por conta da multiplicidade e complexidade de suas funções, o papel de um mero instrumento de "análise qualitativa auxiliada por computador". Imaginemos, por exemplo - pensando aqui em termos do software Atlas.ti, com o qual sou mais familiarizado -, uma formação em sociologia cujas leituras sejam todas fichadas e organizadas dentro de uma Unidade Hermenêutica (UH) muito bem construída e cujos códigos (codes), citações (quotations) e anotações (memos) sejam constantemente retomados a depender das demandas das disciplinas, das seleções de pós-graduação, para construção de projetos e trabalhos. Além disso, o estudante poderá manipular uma arquitetura conceitual expressa em uma ou mais redes (networks) em que os conceitos da sociologia estariam todos eles articulados em um todo coerente, constantemente revisitados e revisados a cada nova leitura.

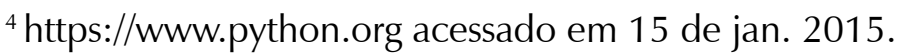


Este panorama demonstra muito mais do que uma "análise qualitativa". Em outras palavras, os CAQDAS - e talvez tenhamos muito em breve que repensar esta denominação - representam novas formas de estruturação da imaginação e da investigação sociológica e, em especial, da sociologia digital. O exponencial aumento da oferta de documentos digitais ou digitalizados (texto, áudio, vídeo e imagem) estimula uma nova forma de tratarmos a informação: mais veloz, mais organizada e, obviamente, articulada com a forma de construção desses softwares.

As potencialidades da análise e recuperação automatizada de informações não podem ser consideradas procedimentos triviais. Uma vez que a aferição da "objetividade" de um estudo sociológico passa necessariamente pela clareza, fidedignidade e publicidade das fontes e dos dados - garantindo, com isto, a possibilidade de replicação das análises - um novo modo de articulação entre os investigadores se mostra necessário. A genialidade do estudo sociológico fruto da imersão solipsista em grandes bibliotecas pensando que "a sorte de sua alma depende de fazer ou não a conjetura correta, neste trecho do manuscrito" (WEBER, 1979, p. 158) agora se esbarra com a produção cada vez mais coletiva em níveis de articulação que extrapolam um único pesquisador, um único centro de pesquisa e as escolas de pensamento nacionais.

Nesse sentido, as lógicas de programação que estruturam tais softwares têm um papel preponderante para avaliarmos "até onde é possível pensar sociologicamente" dentro dos mesmos. Por outro lado, não se trata obviamente de pensarmos esses softwares como a "invenção da roda" no pensamento da sociologia, mas de uma mudança de formato e, para explicar melhor este argumento, vou me remeter a uma conhecida história da sociologia brasileira ${ }^{5}$. Muitos intelectuais comentam o modo como a capacidade intelectual de Florestan Fernandes estaria associada ao fa-

\footnotetext{
${ }^{5}$ Agradeço à pesquisadora Priscila Andreata por esta alusão feita em nosso grupo de estudos.
} 
moso "gavetão" ou fichário de madeira que ele possuía em sua residência na Rua Nebraska no bairro de Brooklin em São Paulo (Sereza, 2005, p. 55-56). O "gavetão" era uma grande quantidade de fichas de cartolina escritas à mão e organizadas segundo temas e autores numa época em que, como sugere Fernando Henrique Cardoso, "a ciência era feita com papel, lápis e caneta"(ib., p. 56). Florestan passava horas reescrevendo, organizando e fazendo buscas neste grande fichário para a montagem de aulas e escrita de artigos.

Como podemos perceber, os novos tempos chegaram e o recurso a um "gavetão digital" através de programas como Atlas.ti e NVivo representam um fenômeno que já existia e, ao mesmo tempo, um elemento revolucionário para a sociologia. A sociologia digital, por seu turno, enfatiza a necessidade de atentarmos não apenas para as mudanças da sociedade digital mas, principalmente, para os impactos de tais mudanças na própria sociologia:

Eu afirmo que os sociólogos não devem apenas estar pensando e estudando como as (outras) pessoas usam as tecnologias digitais, mas também como eles próprios estão cada vez mais se tornando "acadêmicos digitalizados" e as implicações disto para a prática e a definição da própria disciplina da sociologia (Lupton, 2015, p.8)

\section{4 - Sociologia digital: um upgrade necessário}

Em minha opinião, de todas as inquietações da sociologia digital, talvez a mais impactante seja a urgente necessidade de os sociólogos e a sociologia fazerem um "upgrade" de sua clássica fundamentação teórica e metodológica para lidar com novos fenômenos que simplesmente não existiam nas sociedades de cerca de 150 anos atrás, quando do seu surgimento. Principalmente, porque a novidade e os impactos sociais des- 
ses fenômenos têm uma resistência epistemológica em caber dentro de modelos e escolas de pensamento da velha sociologia. Como pensarmos o fenômeno da vigilância digital em escala global, das click farms ${ }^{6}$, a construção da identidade via redes digitais, a privacidade online, a massiva produção de dados digitais e tantos outros assuntos através de teorias cujo horizonte histórico desconhecia tais fenômenos?

Por outro lado, não se trata de promover uma caçada implacável aos clássicos e suas teorias em certa medida obsoletas, mas reconhecer a necessidade de um duplo movimento: reconhecer que os esforços de um eterno retorno às teorias clássicas devem vir acompanhados de um gradiente de reflexão de mesma magnitude em encontrar novas ideias e teorias que produzam inteligibilidade sobre o que está acontecendo no mundo social, buscando, com isto, construir teorias contextualizadas mediante referenciais realmente inovadores:

Uma tarefa intelectual central para a disciplina é reconstruir uma teoria social geral. A Sociologia precisa de uma nova e grande ideia teórica. (Você não está entediado com Weber? Com Durkheim? E talvez até com Marx??) Duas coisas alimentam a grande teoria: a teoria anteriormente produzida e a reflexão sobre o mundo empírico. Em minha opinião, temos hoje demasiados teóricos que não fazem nada além de pensar sobre a teoria anteriormente produzida. (...) Importantes teorias sociais sempre crescem a partir de um extenso trabalho empírico (Abbott, 2000, p. 299).

A sociologia digital fala de pessoas concretas relacionando-se através de artefatos socioculturais criados em um mundo real. É preciso, portanto, questionar sociologicamente muitas das características do "mundo social digital", revelando não apenas aquilo que as pessoas não percebem

${ }^{6}$ Galpões instalados em países pobres do Sudeste Asiático destinados a aumentar a audiência de vídeos, páginas, blogs, games e "likes" em redes sociais mediante baixos pagamentos de mão de obra jovem. Cf. (Arthur, 2013) 
(p.ex. o fato de produzirem dados que enriquecem grandes companhias) mas, sobretudo, aquilo que elas ativamente se recusam em querer saber. Nesse sentido, há uma resistência no mundo social e em muitos artífices da sociologia, que costuma passar despercebida: o investimento emocional que é feito diante do uso da tecnologia é diretamente proporcional ao alto grau de desconhecimento que a esmagadora maioria tem em relação ao modo como as tecnologias funcionam.

Nesse ponto, acho profícuo recorrermos aos clássicos. Em 1900, Georg Simmel descreveu um processo social semelhante aos dias atuais e que se tornou mais agudo em relação à tecnologia digital: o processo da diferenciação subjetiva e objetiva da cultura causado pela divisão do trabalho.

Comparando, por exemplo, com a situação de cem anos atrás, pode-se dizer - reservadas muitas exceções individuais - que as coisas que envolvem e preenchem objetivamente nossa vida, como aparelhos, meios de transporte, produtos da ciência, da técnica e da arte, são incrivelmente cultivadas, mas a cultura dos indivíduos, pelo menos nas classes mais altas, de maneira alguma progrediu, em muitos casos até regrediu (Simmel, 1998, p. 40)

Simmel estava preocupado com o enorme avanço da sua época em produzir uma infinidade de objetos culturais, mas que, paradoxalmente, grande parte dos seus contemporâneos não seria capaz de abarcar no sentido daquilo ter algum interesse ou significado cultural. Após informar as consequências desse processo para a expressão linguística (como, por exemplo, a conversação íntima e a troca de correspondências estariam se esvaziando de conteúdo - e isto, lembremos, em um tempo "pré-emails"), Simmel perguntará sobre a situação dos trabalhadores de sua época:

...quantos trabalhadores - mesmo excetuando-se aqueles da grande indústria propriamente dita - poderiam, hoje, entender a máquina na qual eles trabalham, isto é, entender o espírito investido na máquina? (Simmel, 1998, p. 44) 
Não é preciso replicar a indagação simmeliana para constatarmos que, quanto mais os objetos são investidos de tecnologia coletivamente produzida e acumulada, menos se torna possível a um indivíduo singular recuperar todo o legado cultural cristalizado em objetos como computadores, smartphones, tablets, laptops. E, também, em relação à arquitetura de programação por detrás de sites como Google e redes sociais como Facebook e Twitter. Mas esta recusa ou dificuldade em enfrentar o desconhecimento sobre os fenômenos digitais não seria em si uma postura que não condiz com o ímpeto sociológico? Quais os perigos para os sociólogos em abrir mão do fruto do conhecimento das tecnologias digitais? Gostaria de concluir o artigo tratando dessa questão.

\section{À guisa de conclusão: \\ o temor de uma divisão digital da sociologia}

Compartilho com o temor dos sociólogos que tratam da sociologia digital (Savage; Burrows, 2007; Manovich, 2012; Mahrt; Scharkow, 2013; Lupton, 2015) do perigo de presenciarmos uma cisão insuturável entre aqueles digitalmente habilitados e uma outra parte de pesquisadores completamente desprovidos ou parcamente munidos da mesma expertise. Trazendo o debate para o contexto brasileiro, eu acredito que estamos diante do seguinte cenário. Boa parte dos pesquisadores em sociologia não dão a devida atenção ao grande volume de dados disponibilizados por agências como IBGE, pelos meios de comunicação através de matérias digitais e em relação aos dados que começam a ser produzidos pelos portais da transparência com informações sobre os governos federal, estadual e municipal. Quando algum sociólogo supera a barreira epistemológica do qualitativismo tacanho que impera nos programas de pós-graduação (trabalhos com poucas entrevistas e/ou poucas fontes 
- "amostrados" boa parte das vezes de modo absolutamente caótico e assistemático), ele se encontra desesperado porque simplesmente precisa "terceirizar" a coleta e análise dos dados.

Por outro lado, vem surgindo no Brasil, ainda que timidamente, especialistas em big data. Jovens pesquisadores que aliam a expertise em programação e estatística avançada com a análise sociológica e que manejam grandes bancos de dados com poucas linhas de programação ${ }^{7}$. Entretanto, uma parte desses pesquisadores - que são pejorativamente chamados de "quantitativistas" - de fato guardam um desprezo vigoroso pela teoria sociológica dissociada dos dados. Esta oposição entre dois grupos diferenciados e opostos configura o que foi denominado de data analysis divide (divisão da análise dados) (Manovich, 2012, p.461): uma divisão social do trabalho de coleta, análise e produção de resultados que pode vir a causar graves problemas metodológicos, pois cada uma destas etapas possui, em relação às outras, efeitos de retroalimentação.

Por este motivo, Lev Manovich criou neologismos sobre a existência de três grupos ou "classes sociais" de acesso aos dados (data classes) em nossa "sociedade de megadados" (big data society). Para ele, nós teríamos: a) as pessoas que criam os dados (deliberadamente ou sem saber); b) uma fração menor daqueles que têm os meios para coletá-los e, por fim, c) um grupo ainda menor daqueles que são capazes de analisá-los (Manovich, 2012, p. 470). Da mesma maneira, são compreensíveis metáforas de "inveja dos dados" (Back, 2012, p. 19) ou ainda de "inveja do Google" (Rogers, 2013, p. 206). Ambas expressões que traduzem o fato de as grandes corporações e as think tanks terem a propriedade e o pleno acesso a dados que "se aproximam tanto do tipo como da escala que os cientistas sociais gostariam de gerar por si mesmos, embora sem o refinamento que os pesquisadores poderiam preferir" (ib., p. 206). Este último

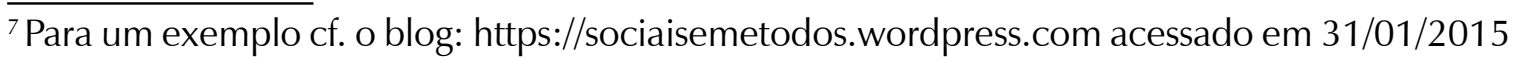


ponto, acerca do refinamento teórico-metodológico das análises desses dados, também é um problema dos big data, que precisa ser considerado.

Tem sido um refúgio cômodo, ainda que não confessado para a sociologia, imaginar que as análises dos demógrafos, estatísticos, economistas e geógrafos acerca de temas "tradicionalmente sociológicos" estariam eivadas de determinismos, reducionismos e/ou um aberto positivismo - no sentido pejorativo que a política acadêmica atribui a estes termos. Tal preconceito seria ainda maior em relação aos matemáticos e programadores que sequer provaram do néctar dos clássicos da sociologia. O problema é que, para alguns autores, a sofisticação intelectual da sociologia não forneceria mais um abrigo seguro que justifique a supremacia - e algumas vezes a arrogância - do sociólogo em relação aos big data digitais (Abbott, 2000, p. 298; Back, 2012, p. 19; Savage; Burrows, 2007, p. 895).

Existem dois aspectos que reforçam a tese da atual fragilidade da sociologia em relação aos big data. O primeiro é que as chamadas Data Brokers (empresas que coletam informações pessoais de consumidores e as revendem ou compartilham com outras empresas) - uma vez alcançado o objetivo de aumentar o consumo de um produto por um determinado perfil de pessoas - prescindem de qualquer sofisticação em suas categorias (Auerbach, 2013; Crawford, 2014). A busca em atingir um estreito segmento do mercado de consumidores ou de eleitores denominado de microtargeting - baseado em um complexo cruzamento de dados de acesso a sites de compras, notícias, grupos em redes sociais digitais, de geolocalização via $\mathrm{IP}^{8}$, não necessitaria de um grau de complexidade em teoria social que costuma ser priorizado na sociologia (Back, 2012, p. 19; Savage; Burrows, 2007, p. 894). Em segundo lugar, mesmo que os sociólogos tivessem acesso a esses dados para suas pesquisas, ou

${ }^{8}$ Acrônimo de internet protocol (protocolo de internet). Trata-se de um endereço que permite identificar cada um dos computadores conectados à web. 
mesmo que estivessem inseridos nessas empresas, seriam necessárias habilidades computacionais para argumentar sócio-tecno-logicamente com os programadores e outros empregados. O problema fundamental, e que não estaria restrito aos sociólogos, é que a nossa formação acadêmica em geral - não me refiro apenas à sociologia - ainda não incorporou a programação e o manejo de softwares como um dos seus conteúdos.

Diante diso, e considerando que a metodologia de survey vem progressivamente deixando de ser - por diversos motivos que não caberiam aqui explorar - o instrumento por excelência de produção de dados sobre o mundo social (Savage; Burrows, 2007), sendo substituído pela mineração digital de dados (digital data mining) e, sobretudo, pela coleta automatizada de metadados ${ }^{9}$, uma desconcertante e desafiadora questão é novamente colocada sobre o papel dos sociólogos:

Os sociólogos não apenas estão enfrentando o fato de que outros atores ou agências podem fazer uso de objetos de dados digitais e, assim, lutar por uma posição como sociólogos enquanto especialistas em pesquisa social; eles também podem ter dificuldades em lidar com as habilidades de computação exigidos por grandes conjuntos de dados digitais (Lupton, 2015, p. 25).

Por fim, os maiores problemas epistemológicos em relação aos dados digitais se referem à possibilidade de assistirmos a um reaparecimento, sobre novas roupagens, de velhas oposições binárias recorrentes nas ciências sociais. Uma delas se refere àquilo que o sociólogo John Goldthorpe (1997) denominou de "escândalo sociológico": a dificuldade ou

\footnotetext{
${ }^{9}$ Literalmente "dados sobre os dados", os metadados podem ser digitais ou não, um catálogo sobre os diferentes tipos de livros e onde encontrá-los em uma biblioteca até as informações de acesso em um servidor de internet podem ser considerados metadados. Eles têm, como função, informar-nos sobre o conteúdo da informação (o que tipo de informação os objetos contem), o contexto da informação (indica quem, o que, porque, onde e como associados à informação) e a estrutura da informação (a relação entre os diferentes tipos de informações coletadas). Para mais detalhes cf. (BACA, 2008).
} 
ausência de integração entre a teoria sociológica e a pesquisa da sociedade. $\mathrm{O}$ tratamento dos dados digitais poderia atualizar a divisão entre aqueles que seriam capazes de coletar e analisar os dados mediante ferramentas digitais de análise e os que teorizam sobre o mundo social digital. A consequência disto é empobrecer o refinamento da reflexão sociológica em dar conta da novidade dos dados digitais.

Outro possível problema diz respeito a uma reedição da querela entre métodos qualitativos e quantitativos de análise. Grande parte das análises de big data, por conta da evidente extensão dos dados, estão baseadas em lógicas de programação automatizadas, fundamentadas em natural language processing (processamento de linguagem natural) um campo de convergência entre a linguística e a inteligência artificial. Em ferramentas de sentiment analysis (análise de sentimentos) para redes sociais (Agarwal et al., 2011) são utilizados algoritmos sofisticados que estimam os sentimentos dos usuários sobre temas específicos, tais como marcas de produtos, candidatos em campanha eleitoral etc., mediante ausência/presença de palavras-chave, encadeamentos e expressões. Além disso, é possível a estes algoritmos identificar, no total de usuários de redes sociais digitais, aqueles que seriam os detentores de uma opinião mais influente (Wright, 2009).

É provável que estes poucos exemplos evoquem uma profunda desconfiança nos sociólogos, haja vista que não poderia existir sociologia sem os processos de compreensão e interpretação da realidade, tarefas que demandam tempo, paciência e profunda imersão do pesquisador no mundo e nos problemas sociais. Trata-se de uma questão ainda em aberto, conciliar as análises automatizadas dos big data com os métodos tradicionais da sociologia. Uma saída que venho utilizando é a combinação de leitura e interpretação de matérias de jornal com o tratamento automatizado por meio de categorias construídas através da teoria fun- 
damentada nos dados (Strauss; Corbin, 2008). Ao trabalhar dessa forma, é possível "quantificar a qualidade" e traçar um panorama amplo dos dados. Uma das principais desvantagens deste procedimento é o tempo gasto no processo de codificação e a consequente necessidade de um corpo de codificadores muito bem treinados.

Acredito que, ao superarmos tais desconfianças e nos instrumentalizarmos tecnologicamente nessas ferramentas digitais, será possível afirmar os limites e possiblidades de utilização dos big data e avaliar como as metodologias digitais de análise da sociedade estão impactando o modo como fazemos sociologia. É tarefa da sociologia digital debater estas questões traçando os contornos do novo panorama. Lembrando sempre que as máquinas e a tecnologia não são o "outro", mas devem ser concebidas segundo a imagem e semelhança daqueles que a construíram:

Todo artefato, uma máquina por exemplo, somente pode ser interpretado e compreendido a partir do sentido que a ação humana (com finalidades possivelmente muito diversas) proporcionou (ou pretendeu proporcionar) à sua produção e utilização; sem o recurso a este sentido permanecerá inteiramente incompreensível. O compreensível nele é, portanto, sua referência ao comportamento humano (Weber, 1994, p. 5)

Leonardo Fernandes Nascimento - Doutor em sociologia pelo Instituto de Estudos Sociais e Políticos (IESP), da Universidade do Estado do Rio de Janeiro (UERJ), colaborador no Programa de Pós-graduação em Ciências Sociais da UFBA (PPGCS/UFBA) e desenvolve pesquisas sobre Sociologia Digital, "Big Data Social Science" e análise de mídia.

$\triangle$ leofn@yahoo.com.br 
Sociologias, Porto Alegre, ano 18, no 41, jan/abr 2016, p. 216-241

\section{Referências}

1. ABBOTT, A. Reflections on the Future of Sociology. Contemporary Sociology, v. 29, n. 2, mar. 2000. pp. 296.

2. AGARWAL, A. et al. Sentiment Analysis of Twitter Data. In: Workshop on Language in Social Media (LSM 2011), 2011, Portland, Oregon. Proceedings... Portland, Oregon: Association for Computational Linguistics, 2011. p. 30-38. Disponível em: <http://dl.acm.org/citation.cfm?id=2021109.2021114>. Acesso em: 23 jan. 2015.

3. ARTHUR, C. How low-paid workers at "click farms" create appearance of online popularity. The Guardian, [S.I.], 2 ago. 2013. Section Tech. Disponível em: $<$ http://www.theguardian.com/technology/2013/aug/02/click-farms-appearance-online-popularity>. Acesso em: 5 fev. 2015.

4. AUERBACH, D. You Are What You Click: On Microtargeting. The Nation, $13 \mathrm{fev}$. 2013. Section Cultural Criticism and Analysis. Disponível em: <http://www.thenation.com/article/172887/you-are-what-you-click-microtargeting? page $=$ full $>$. Acesso em: 24 fev. 2015.

5. BACA, M. Introduction to Metadata. [S.I.]: Getty Publications, 2008.

6. BACK, L. Live sociology: social research and its futures. The Sociological Review, v. 60, 2012. pp. 18-39.

7. BEER, D.; BURROWS, R. Sociology and, of and in Web 2.0: Some Initial Considerations. Sociological Research Online, 2007. Disponível em: <http://www. socresonline.org.uk/cgi-bin/perlfect/search/search.pl?q=sure\&showurl =\%2F12\% 2F5\%2F17.html>. Acesso em: 22 jan. 2015.

8. BEER, D.; BURROWS, R. Popular Culture, Digital Archives and the New Social Life of Data. Theory, Culture \& Society, 16 abr. 2013.

9. BOURDIEU, P.; PASSERON, J. C.; CHAMBOREDON, J. C. Ofício de Sociólogo: metodologia da pesquisa na sociologia. Petrópolis: Vozes, 2004.

10. BOYD, D.; CRAWFORD, K. Critical Questions for Big Data. Information, Communication \& Society, v. 15, n. 5, 1 jun. 2012. pp. 662-679.

11. CHRISTAKIS, N. A. Let's Shake Up the Social Sciences. The New York Times, [S.I.], 19 jul. 2013. Disponível em: <http://www.nytimes.com/2013/07/21/opinion/sunday/lets-shake-up-the-social-sciences.html>. Acesso em: 1 fev. 2015.

12. CRAWFORD, K. When Big Data Marketing Becomes Stalking. Scientific American, 28 fev. 2014. Disponível em: <http://www.scientificamerican.com/ article/when-big-data-marketing-becomes-stalking/>. Acesso em: 24 fev. 2015. 
13. DURKHEIM, E. As regras do método sociológico. São Paulo: Martins Fontes, 2007.

14. FARRELL, D.; PETERSEN, J. C. The Growth of Internet Research Methods and the Reluctant Sociologist. Sociological Inquiry, v. 80, n. 1, 2010. pp. 114-125.

15. GOLDTHORPE, J. H. The integration of sociological research and theory: grounds for optimism at the end of the twentieth century. Rationality and Society, v. 9, 1 nov. 1997. pp. 405-426.

16. HORST, H. A.; MILLER, D. Digital Anthropology. [S.I.]: Bloomsbury Academic, 2012.

17. HUANG, R. R-based Qualitative Data Analysis. [S.I.]: [s.n.], 2014.

18. JORDAN, T. Internet, Society and Culture: Communicative Practices Before and After the Internet. Reprint edition ed. [S.I.]: Bloomsbury Academic, 2014.

19. LAGE, M. C.; GODOY, A. S. Computer-aided qualitative data analysis: emerging questions. RAM. Revista de Administração Mackenzie, v. 9, n. 4, jun. 2008. pp. 75-98.

20. LUPTON, D. Digital Sociology. [S.I.]: Routledge, 2015.

21. MAHRT, M.; SCHARKOW, M. The Value of Big Data in Digital Media Research. Journal of Broadcasting \& Electronic Media, v. 57, n. 1, 1 jan. 2013. pp. 20-33.

22. MANGABEIRA, W. C.; LEE, R. M.; FIELDING, N. G. Patterns of adoption, modes of use and representations about technology: CAQDAS users in he United Kingdom, in the mid-1990s. Sociologias, n. 5, jun. 2001. pp. 20-57.

23. MANOVICH, L. Trending: the promises and the challenges of big social data. 2012. Disponível em: <http://manovich.net/content/04-projects/067-trendingthe-promises-and-the-challenges-of-big-social-data/64-article-2011.pdf > . Acesso em: 24 fev. 2015.

24. PRIOR, N.; ORTON-JOHNSON, K. Digital Sociology: Critical Perspectives. [S.I.]: Palgrave Macmillan, 2013.

25. PUEBLA, C.; A, C. Computer-assisted qualitative analysis. Sociologias, n. 9, jan. 2003. pp. 288-313.

26. ROGERS, R. Digital Methods. [S.I.]: MIT Press, 2013.

27. R TEAM CORE. R: A language and environment for statistical computing. Vienna, Austria: R Foundation for Statistical Computing, 2014. 
28. SAVAGE, M.; BURROWS, R. The Coming Crisis of Empirical Sociology. Sociology, v. 41, n. 5, 1 out. 2007. pp. 885-899.

29. SEREZA, H. C. Florestan: a inteligência militante. [S.I.]: Boitempo Ed., 2005. 30. SIMMEL, G. Simmel e a modernidade. Brasília: Ed. da Universidade de Brasília, 1998.

31. STRAUSS, A.; CORBIN, J. Pesquisa qualitativa: técnicas e procedimentos para o desenvolvimento de teoria fundamentada. Porto Alegre: Artmed, 2008.

32. TEIXEIRA, A. N.; BECKER, F. New possibilities for qualitative research via CAQDAS systems. Sociologias, n. 5, jun. 2001. pp. 94-113.

33. WEBER, M. Ensaios de Sociologia. Rio de Janeiro: Zahar Editores, 1979.

34. WEBER, M. Economia e Sociedade. 3a. ed. Brasília: Editora UNB, 1994.

35. WITTE, J. C. A Ciência Social digitalizada: avanços, oportunidades e desafios. Sociologias, v. 14, n. 31, 2012. Disponível em: < http://seer.ufrgs.br/index.php/ sociologias/article/view/34927>. Acesso em: 27 jul. 2014.

36. WRIGHT, A. Mining the Web for Feelings, Not Facts. The New York Times, [S.I.], 24 ago. 2009. Disponível em: <http://www.nytimes.com/2009/08/24/technology/internet/24emotion.html>. Acesso em: 23 jan. 2015.

37. WYNN, J. R. Digital Sociology: Emergent Technologies in the Field and the Classroom. Sociological Forum, v. 24, n. 2, 1 jun. 2009. pp. 448-456.

Recebido em: 24/02/2015

Aceite final em: 26/05/2015 